\title{
EDITORIAL
}

\section{Metabolic Syndrome}

Elizabete Viana de Freitas $^{(\sqrt{ })}$ and Kalil Lays Mohallem ${ }^{(1)}$

Hospital Pró-cardíaco, Rio de Janeiro, RJ - Brazil

\section{Introduction}

Metabolic Syndrome (MS) is a complex disorder characterized by a group of Risk Factors (RF), including changes in glycemic levels, insulin resistance, lipid profile, blood pressure levels and central obesity (visceral adipose tissue - VAT), which increase the incidence of cardiovascular diseases often associated with ageing. ${ }^{1}$

It is estimated to affect over $20 \%$ of the global adult population, and women are at greater risk. Central (visceral) obesity is thought to be the predominant RF for MS, especially among overweight and low-educated elderly. ${ }^{2}$

Central obesity can be called an underlying risk factor for cardiovascular disease (ASCVD). It is called this because it raises the risk for ASCVD through other RFs, including major RFs (hypercholesterolemia, hypertension, hyperglycemia) and emerging RFs (atherogenic dyslipidemia, insulin resistance, proinflammatory state, prothrombotic state). The constellation of major and emerging RFs that make up the MS can be called metabolic RFs and, since predictions estimate that 50\% of adults will be classified as obese by 2030, it is likely that MS will be a significant problem for health services and a drain on health economies. ${ }^{3}$

Abdominal obesity does not always occur in individuals with elevated BMI. It was recognized as early as 1981 that normal weight, metabolically obese individuals existed due to the presence of excessive visceral fat deposits. ${ }^{4}$

\section{Keywords}

Metabolic Syndrome; Risk Factors; Prevention and Control; Obesity; Dyslipidemias; Hypertension; Diabetes Mellitus, Elderly.
In this issue of IJCS, Almerida et al., ${ }^{5}$ present a study with 159 patients from Lagarto/Sergipe, whose mean age was $70.9 \pm 7.5$ years. Central obesity was present in $43.2 \%$ of men and $56.89 \%$ of women and was associated with changes in HDL-C levels. The study adds to the understanding of this condition in a Brazilian region where few studies of this kind have been carried out and confirms its high prevalence.

It is important to highlight that measuring waist circumference in older adults can be difficult due to the curvature of the spine and vertebrae and walking or standing limitations. It may be necessary to adjust the cutoff for waist circumference based on age and ethnicity. Sex-specific cut-off criteria for the general population are $\geq 102 \mathrm{~cm}$ (40 in) for men and $\geq 88$ for women (35 in). ${ }^{1}$ See Table 1.

When the BMI is used as a measure of obesity, only a modest association with cardiovascular RFs is found.

Table 1 - ATP III Clinical identification - Three or more risk factors present

\begin{tabular}{lc}
\hline Risk Factor & Defining Level \\
\hline Waist circumference & $\geq 102 \mathrm{~cm}(>40 \mathrm{in})$ \\
Men & $\geq 88 \mathrm{~cm}(325 \mathrm{in})$ \\
Women & $\geq 1150 \mathrm{mg} / \mathrm{dL}$ \\
Triglycerides & $<40 \mathrm{mg} / \mathrm{dL}$ \\
HDL-C & $<50 \mathrm{mg} / \mathrm{dl}$ \\
Men & $\geq 130 / \geq 85 \mathrm{mmHG}$ \\
Women & $\geq 110 \mathrm{mg} / \mathrm{dL}$ \\
Blood Pressure & \\
Fasting Glucose & \\
\hline The American Diabetes Association established a cut point of $100 \mathrm{mg} / \mathrm{dL}$
\end{tabular}


However, when abdominal obesity measurements, such as waist circumference or waist-hip ratio, are included as a measure of abdominal adiposity, a strong association with cardiovascular and metabolic syndrome RFs is found. ${ }^{6}$ Therefore, it is important to measure the waist circumference in the patient's routine examination.

Evidence shows that one of the single most important lifestyle changes for the prevention of many chronic diseases is exercise. For this reason, exercise is now recognized as a medical treatment to improve quality of life and functioning in the elderly. There is growing evidence that regular and consistent exercise significantly reduces abdominal fat deposits, independent of weight loss. ${ }^{7}$

A systematic review and meta-analysis were conducted by Ostman et al. to determine whether exercise reversed various indices of metabolic syndrome, including body composition, blood

\section{References}

1. Sociedade Brasileira de Cardiologia. Sociedade Brasileira de Endocrinologia e Metabologia. Sociedade Brasileira de Diabetes. Sociedade Brasileira para Estudos da Obesidade. I Diretriz Brasileira de Diagnóstico e Tratamento da Síndrome Metabólica. Arq Bras Cardiol. 2005;84(supl 1):1-28.

2. Park Y-W, Zhu S, Palaniappan L, Heshka S, Carnethon MR, Heymsfield $\mathrm{SB}$. The metabolic syndrome: prevalence and associated risk factor findings in the US population from the third National Health and nutrition examination survey, 1988-1994. Arch Intern Med. 2003;163(4):427-36.

3. Saad MAN, Cardoso GP, Martins WA,Velarde LG, Cruz Filho RA. Prevalence of Metabolic Syndrome in Elderly and Agreement Among Four Diagnostic Criteria. Arq Bras Cardiol. 2014;102(3):263-9.

4. Ruderman NB, Schneider SH, Berchtold P. The "metabolically-obese," normal-weight individual. Am J Clin Nutr. 1981;34(8):1617-21 cholesterol, fasting blood glucose, fasting insulin, blood pressure and clinical outcome. When the combined exercise group was compared with the control group, the mean difference of: waist circumference was $-3.80 \mathrm{~cm}(95 \%$ CI $-5.65,-1.95, p<0.0001)$; systolic blood pressure was $-3.79 \mathrm{mmHg}(95 \% \mathrm{CI}$ $-6.18,-1.40, p=0.002)$; and HDL was 0.14 (95\% CI $0.04,0.25, p=0.009)$. The improvements in waist measurement would suggest that the long-term risks associated with MS were reduced, although the program needs to be tailored to the individual whilst aiming to deliver optimal effects. ${ }^{8}$

Due to population characteristics, further and larger studies are required to improve the diagnosis and treatment of MS in older adults and, consequently, reduce the cardiovascular risk of this growing and vulnerable population.

5. Almeida AC, Oliveira CC, Costa ED, Deiró AQ. Association between Central Obesity and Biochemical Markers of Cardiometabolic Risk in Elderly Attended in Geriatric Ambulatory - Lagarto/SE. Int J Cardiovasc Sci. 2020;33(3):245-251.

6. Brooks GC, Blaha MJ, Blumenthal RS. Relation of C-reactive protein to abdominal adiposity. Am J Cardiol. 2010;106(1):56-61.

7. Davidson LE, Hudson R, Kilpatrick K, Kuk JL, McMillan K, Janiszewski $\mathrm{PM}$, et al. Effects of exercise modality on insulin resistance and functional limitation in older adults: a randomized controlled trial. Arch Intern Med. 2009;169(2):122-31.

8. Ostman C, Smart NA, Morcos D, Duller A, Ridley W, Jewiss D. The effect of exercise training on clinical outcomes in patients with the metabolic syndrome: a systematic review and meta-analysis. Cardiovasc Diabetol 2017;16(1):110. 